\title{
Estudo de representações sociais sobre Física Quântica
}

\author{
A study on social representations of \\ Quantum Physics
}

\author{
Thaís Rafaela Hilger \\ Marco Antonio Moreira \\ Fernando Lang da Silveira
}

\begin{abstract}
Resumo
Este trabalho apresenta resultados preliminares de uma investigação sobre possíveis representações sociais compartilhadas por diferentes grupos sociais, como estudantes do Ensino Médio, por exemplo. O objetivo é, utilizando análise multidimensional, identificar e caracterizar possíveis representações sociais a partir dos dados obtidos com o uso de testes de associação escrita e numérica de conceitos (TAEC e TANC). A compreensão dessas representações pode auxiliar no processo de aprendizagem significativa da Física Quântica, bem como em avaliar a influência dos meios de divulgação que propagam conceitos científicos - ou quase científicos - sobre as idéias dos indivíduos a respeito deste tema.
\end{abstract}

Palavras-chave: Física Quântica, representações sociais, aprendizagem significativa.

\section{Abstract}

This paper presents preliminary findings of a research on possible social representations shared by different social groups such as, for example, high school students. The objective is to identify some features of these representations applying multidimensional scaling to data gathered through written and numerical word association tests (TAEC and TANC). The identification of such representations might help in the process of meaningful learning of quantum physics as well as in assessing the influence of how scientific concepts are disseminated by the media on how individuals grasp the meaning of these concepts.

Keywords: quantum physics, social representations, meaningful learning. 


\section{Introdução}

Atualmente alguns termos científicos têm apresentado grande destaque nos meios de comunicação para explicar fenômenos dos mais diferentes tipos. Devido à freqüente exposição, acredita-se que a Física Quântica possa ser alvo de interesse público e, por este motivo, apresentar diferentes significados para a população. Em diversas ocasiões este conceito é apresentado erroneamente, ou de modo muito simplificado, adotando significados que não são aceitos pela comunidade de físicos.

Neste panorama, as informações propagadas pelos meios de divulgação (boas ou não tão boas) podem exercer grande influência na formação do conhecimento prévio, uma vez que este pode não ser adequado e, portanto, criar um subsunçor inadequado para novos conhecimentos. Acredita-se que estes significados, ao serem incorporados pelos sujeitos à sua estrutura cognitiva, possam atuar como barreira à aprendizagem significativa de um conceito tal como ele é aceito na comunidade científica. As representações sociais são o reflexo do conteúdo que circula nesses meios, pois é através deles que a população em geral têm acesso ao conhecimento produzido no meio acadêmico.

Este conhecimento, produzido no meio científico erudito, constitui o chamado universo reificado e apresenta regras metodológicas e teóricas objetivas e muito rigorosas. Trata-se de um universo restrito, composto por atividades intelectuais e pelas ciências que produzem o conhecimento em unidades especializadas e hierarquizadas.

Por outro lado, as relações provenientes do cotidiano e do senso comum, onde são elaboradas as representações sociais, formam o chamado universo consensual. O conhecimento produzido neste universo não apresenta regras pré-estabelecidas ou alguma objetividade, ao contrário, utiliza-se de uma lógica própria. A sociedade em geral participa deste universo de forma igualitária, onde os indivíduos podem expressar-se segundo seus próprios valores: todas as teorias elaboradas para explicar o cotidiano têm igual valor e, quando compartilhadas, regem certos comportamentos habituais.

Entre estes dois universos encontram-se os meios de divulgação, como, por exemplo, internet, cinema, revistas, livros, televisão, radio, etc., que tentam traduzir o conhecimento, proveniente do universo reificado, para a população que integra o universo consensual. Além desses meios há também pessoas que fazem essa transformação da informação, atuando em suas profissões, como é o caso de professores, jornalistas, apresentadores e palestrantes, cientistas amadores, etc.

Devido à enorme quantidade de conhecimentos produzidos, os conteúdos científicos recebem cada vez mais atenção e, muitas vezes, dominá-los é sinal de status. Além disso, com 
bastante freqüência os assuntos veiculados fazem referência ao universo reificado, e a população naturalmente sente necessidade de posicionar-se a respeito dele e desses temas, propiciando a elaboração de representações sociais. Assim, surge na sociedade atual uma nova espécie de senso comum, "permeado pela razão e submetido à autoridade legítima da ciência. Este é um conhecimento de segunda mão que se estende e estabelece constantemente em um novo consenso sobre cada descobrimento e cada teoria" (Moscovici \& Hewstone, 1984, p. 685). Esse novo conhecimento, seja ele representação social ou não, pode atuar como subsunçor para a aprendizagem significativa.

\section{Referenciais teóricos}

\section{Aprendizagem Significativa}

A teoria da aprendizagem significativa proposta por Ausubel (Ausubel, 2000) refere-se ao processo de aquisição de um corpo organizado de conhecimentos em situação formal de ensino. Neste processo, a variável mais importante para o sucesso da aprendizagem é o conhecimento prévio do aprendiz, constituído pelos denominados subsunçores. Aprender significativamente é dar significado a uma nova informação, é relacioná-la a algum conhecimento especificamente relevante já presente na estrutura cognitiva do aprendiz de forma clara e estável, disponível para uma interação cognitiva.

$\mathrm{Na}$ aprendizagem significativa há interação entre os conhecimentos novos e os subsunçores do aprendiz, provocando modificações em ambos e formando um novo conhecimento, cujas características serão obtidas a partir de ambos. Esta ligação que ocorre entre conhecimentos é designada "ancoragem cognitiva", pois a nova informação ancora-se, liga-se interativamente à pré-existente. Assim, o significado lógico do conteúdo passa a ter significado psicológico e é incorporado à estrutura cognitiva do aprendiz (Moreira, 1997, p. 2).

Este processo é chamado por Ausubel de assimilação. Além dele, Ausubel complementa sua teoria com os processos de diferenciação progressiva, no qual ocorre o refinamento, detalhamento, enriquecimento, do subsunçor, elevando seu grau de especificidade e sua capacidade de ancoragem, e o de reconciliação integradora, responsável pelas relações de semelhanças e diferenças entre os subsunçores, explorando essas relações e os recombinando.

Para Ausubel, "todas as experiências passadas de aprendizagem influenciam, exercem efeitos positivos ou negativos, na nova aprendizagem ... em virtude do impacto sobre as propriedades relevantes da estrutura cognitiva" (Ausubel, 2000, p. 8), isto é, atuam sobre o conhecimento prévio do sujeito. A teoria da aprendizagem significativa parte da idéia central da ancoragem cognitiva, interativa, de conhecimentos novos nos conhecimentos prévios. Assim 
sendo, a teoria das representações sociais relaciona-se intimamente com a teoria da aprendizagem significativa, pois as representações fazem parte do conhecimento pré-existente do aluno e, em situação de aprendizagem, podem influenciá-la positiva ou negativamente.

Sabendo que um subsunçor pode ter significado para o sujeito mesmo sem corresponder ao que é aceito pela comunidade científica, decorre daí a importância, para o ensino, de se conhecer que significados são esses e buscar entender como estão relacionados e estruturados. De posse de conhecimentos acerca dos subsunçores, é possível modificá-los e até evitá-los, caso seja necessário, para que a aprendizagem seja significativa, porém com significados aceitos no contexto da matéria de ensino. Nos subsunçores estão inclusas todas as formas de conhecimento e todos os elementos cognitivos que possam participar desse conhecimento: conceitos, imagens, esquemas de assimilação, concepções alternativas, modelos mentais, etc. A representação social de um conceito também está contida nesse conjunto e pode participar no processo cognitivo, fazendo papel de subsunçor.

\section{Representações sociais}

Uma representação social "é constituída de um conjunto de informações, de crenças, de opiniões e de atitudes a propósito de um objeto dado. Além disso, este conjunto de elementos é organizado e estruturado" (Abric, 2001, p. 18). Por isso, além de conhecer seu conteúdo e identificar sua organização e estrutura, é preciso saber como estes elementos se relacionam com a estrutura cognitiva do sujeito. As representações sociais apresentam sua organização em torno de um núcleo central e de uma periferia. São construídas socialmente, mas são incorporadas a estruturas cognitivas individuais, de modo que podemos caracterizá-las como representações sócio-cognitivas.

As idéias mais importantes e estáveis estão inclusas no núcleo da representação, que é sempre consensual e compartilhado. O núcleo outorga significado à representação e atua organizando, estabilizando e unificando as idéias sobre o objeto; por isso, caracteriza a identidade de cada grupo. Basta que o núcleo de duas representações seja diferente para que se tenha duas representações distintas.

Na periferia são armazenados os elementos mais acessíveis e flexíveis, cuja existência permite atualizar a representação e adaptá-la ao contexto, protegendo o núcleo e garantindo a individualidade de cada sujeito. Nela, contradições e incorporações individuais são permitidas, sendo o complemento indispensável do núcleo, pois aparece em relação direta com ele. É o núcleo que determina o valor, a função e a presença da periferia. 
"É a existência desse duplo sistema que permite entender uma das características essenciais da representação social que poderia parecer contraditória: são às vezes estáveis e móveis, rígidas e flexíveis. Estáveis e rígidas porque estão determinadas por um núcleo central profundamente ancorado no sistema de valores compartilhado pelos membros do grupo; móveis e flexíveis porque são alimentadas por experiências individuais $e$ integram a vivência e a situação específica, a evolução das relações e das práticas sociais nas quais os indivíduos ou os grupos estão inseridos" (op. cit., p. 27).

As pessoas formam uma representação social e buscam informações a respeito de um objeto apenas após adotarem um posicionamento e em função desse posicionamento. Uma representação social é uma modalidade de conhecimento que tenta elaborar condutas comportamentais e comunicativas de indivíduos no decorrer de suas interações com o grupo. É um meio de explicação das atividades sociais que permite compreender e antecipar comportamentos e práticas sociais.

Assim, as representações sociais são cunhadas em grupos sociais, nos quais os sujeitos comunicam-se a respeito de um objeto, interagindo com ele e representando-o. Cada grupo relaciona-se de modo diferente com o objeto e cria sua versão de um conhecimento. Portanto, nem todos os grupos compartilham a mesma representação. Existe então uma diversidade de representações sociais, que são construídas conforme as relações com o objeto e de acordo com fatores de emergência.

Basicamente são três as mais importantes condições de emergência que definem a pluralidade de representações sociais criadas por diferentes grupos sociais:

1) dispersão da informação: os indivíduos não têm acesso a todas as informações sobre um conhecimento produzido no universo reificado e diferentes grupos têm acesso diferente às mesmas informações, ou até mesmo acesso a informações distintas sobre um mesmo objeto. Isto ocorre porque a informação disseminada pode não apresentar o mesmo significado para todos os grupos sociais, e porque sofre alterações e distorções no processo de sua transmissão.

2) focalização: faz com que aspectos do objeto sejam mais interessantes e impede que o sujeito tenha uma visão global sobre ele. Esses aspectos são determinados pelo acesso a informação ou mesmo por interesses, crenças, ideologias e valores.

3) pressão à inferência: após a constatação de um fenômeno, surge a necessidade de tomada de posição sobre ele. Este processo leva tempo, pois neste período o sujeito sente-se pressionado, mas não conhece o suficiente sobre o objeto. Assim, a adesão às opiniões 
dominantes do grupo é favorecida e possibilita a estabilização do conhecimento relativo ao objeto da representação. (Moliner, 1996, p. 33).

Complementando essas condições, é necessário que o grupo relacione-se com o objeto a ser representado e que este objeto tenha valor para o grupo, razões pelas quais os sujeitos buscam representá-lo. $O$ objeto deve apresentar uma interpretação polimórfica o suficiente para que o sujeito apóie-se na opinião do grupo e a compartilhe, criando interações e comportamentos dirigidos para o grupo e do grupo para os indivíduos. Além dessas condições, também o grupo deve apresentar ausência de ortodoxia, isto é, não deve estar submetido a princípios que controlem seus pensamentos e atitudes em relação ao objeto, o que impediria a busca por explicações alternativas (op.cit., pp. 35-48).

Depois de satisfeitas essas condições de emergência, dois processos são envolvidos na elaboração de uma representação social. Esses processos auxiliam no entendimento também do funcionamento das representações sociais.

Um dos processos que atua na elaboração de uma representação social é a objetivação, que traduz um conceito ou idéia por meio de imagens, permitindo que o objeto seja interpretado. Alguns elementos comuns sobre o objeto são previamente selecionados entre os dados fornecidos no decorrer de processos comunicativos e, depois, esses elementos são integrados em um todo coerente e retidos pelo indivíduo.

Simultaneamente, ocorre outro processo, o da ancoragem, que se refere "à integração cognitiva do objeto representado dentro do sistema de pensamento preexistente e às transformações derivadas desse sistema" (Jodelet, 1986, p. 486). Trata-se da inserção do objeto dentro de uma estrutura previamente constituída e familiar, fornecendo um contexto inteligível ao objeto. Assim o objeto é traduzido em sentido e significado, instrumentalizando o conhecimento e enraizando-o na estrutura cognitiva.

A formalização do conhecimento ocorre após esses dois processos e possui o objetivo de familiarizar o sujeito ao objeto: "a finalidade de todas as representações é tornar familiar algo não familiar, ou a própria não-familiaridade" (Moscovici, 2003, p. 54). O novo objeto deve ser entendido e explicado a partir de sistemas familiares ao sujeito, o que garante a relação entre as funções cognitivas básicas, a representação social e sua função social (Jodelet, 1986, pp. 486-492).

Resumidamente, pode-se dizer que conhecimentos são produzidos nos universos reificados e, através dos meios de comunicação, são extrapolados, em uma versão supostamente acessível, para o meio social - que constitui o universo consensual. Os sujeitos sentem pressão em posicionar-se em relação às informações que aparecem, de modo insistente, nesses meios de comunicação. Para manifestar-se sobre o novo conhecimento, em parte desconhecido, precisam processar estas informações através da objetivação e da ancoragem. 
Ao final desses processos, tem-se uma representação construída e compartilhada socialmente e que, com freqüência, está distante daquela proveniente do universo reificado. Surge, assim, um novo e cientifizado senso comum, cujos efeitos sobre a compreensão e explicação da realidade podem atuar como subsunçores, favorecendo ou impedindo a aprendizagem significativa. Desta forma, é necessário investigar, por exemplo, que idéias sobre a "Física Quântica" circulam no meio escolar e acadêmico, possibilitando a detecção de possíveis representações sociais dessa área da Física.

\section{Os meios de comunicação e a Física Quântica}

O crescente alcance dos meios de comunicação é um dos responsáveis pela disseminação de termos "científicos" como justificativa e explicação de fenômenos cotidianos e um desses termos é a "Física Quântica". Conhecer essas apropriações indevidas que circulam no universo consensual é de suma importância para o estudo das representações sociais, pois podem participar na elaboração dessas representações.

São apresentados a seguir trechos transcritos de algumas obras contemporâneas que apresentam em seu título a expressão "Quântica" como chamariz. Não é a pretensão dissertar sobre o mérito das ligações entre a Física Quântica e os temas abordados por estes autores, mas apenas mostrar que fazem parte da dispersão de informações sobre o assunto e que não há necessariamente aceitação por parte dos físicos sobre essas abordagens.

Mas, se o holismo pretende ter algum significado (...) deve estar bem fundamentado numa verdadeira física da consciência, numa física que possa alicerçar a unidade da consciência e relacioná-la tanto à estrutura do cérebro como às características comuns de nossa percepção corriqueira. Acho que para conseguir isto devemos nos voltar para a Mecânica Quântica (Zohar, 1990, p. 87).

A idéia de uma "sociedade quântica" procede da conviç̧ão de que todo um paradigma novo está surgindo a partir de nossa descrição da realidade quântica, e de que esse paradigma pode estender-se a ponto de alterar radicalmente nossa percepção de nós mesmos e do mundo social no qual queremos viver. Estou convencida de que uma apreciação mais ampla da natureza revolucionária da realidade quântica e dos possiveis vínculos entre os processos quânticos e os processos cerebrais pode nos oferecer os fundamentos conceituais que necessitamos para realizar uma "revolução positiva" na sociedade (Zohar, 2000, p. 20). 
Estou convencida de que a consciência humana é de fato mecânico-quântica em suas origens e de que a mecânica dessa consciência quântica dá literalmente à nossa mente, ao nosso eu e às nossas relações sociais aspectos tanto de onda quanto de partícula (op. cit., p. 129).

Com a intenção de preencher esta lacuna é que está em pleno desenvolvimento a medicina quântica integral com sua metodologia holística de abordagem do ser humano como um todo, dentro de uma totalidade, como um universo dentro de outro mais abrangente: o universo cósmico (Mattos, 2001, p. 34).

O organismo humano possui um campo quântico, formado por subpartículas atômicas denominadas neutrinos. À primeira vista, isto parece uma afirmação estranha e fantasiosa, mas pode ser comprovada, e o estudo acurado da física quântica fornecerá os subsídios teóricos necessários ao seu entendimento. As características deste campo quântico podem ser assim resumidas em três características principais: 1) É monopolar ... 2) O campo é predominantemente neutrínico ... 3) $O$ campo neutrínico não interage com campos eletromagnéticos (op. cit., p. 60).

$\mathrm{Na}$ verdade só a física quântica pode explicar seus mecanismos [da Homeopatia] de ação, como se depreende do que foi acima descrito. Os homeopatas fariam um grande favor a seus clientes, explicando-Ihes de maneira científica o funcionamento de sua especialidade. Esta providência além de mais adequada à época em que vivemos, muito contribuiria para estabelecer de maneira nítida os limites de sua atuação, além do que contribuiria para aumentar a confiança em seus métodos, que se afiguram como no mínimo estranhos para o público em geral (op. cit., p. 191).

A energia de nossos corpos, os quais, diga-se de passagem, são muito mais energia do que matéria sólida como pode parecer. A Física Quântica já provou isso, quando mostrou a relação entre massa e energia: $E=m c 2$. Por tudo isso, a verdadeira inteligência é quântica, porque vai além do emocional, do material e do mental ... a tendência é que cada vez mais se descubra a respeito das relações existentes no universo, o que inclui nosso corpo quântico que é o nosso universo pessoal (Menezes, 2006, p. 19).

Em termos de criatividade, é preciso ter o pensamento livre para criar, e a disciplina para sistematizar, para avaliar e pôr em andamento. Isso é obtido com exercícios que trabalham o equilíbrio quântico que leva ao 
desenvolvimento de uma incrível capacidade de ter bom humor, que é também chave para o sucesso (op. cit., p. 65).

A Física Quântica trouxe, definitivamente, para o cenário da ciência, a consciência do observador como responsável por alterações no comportamento das partículas. É o que tradicionalmente se conhecia como poder da mente, ou poder do pensamento, que para um cientista mecanicista não passa de especulação mística (Lima, 2007, p. 13).

$\mathrm{Na}$ definição e interpretação do Universo, os cientistas abandonaram a materialidade e partiram para conceitos. Esses conceitos, a partir de formulações matemáticas, nos descreveram um Universo fantástico, rico em oportunidades à nossa disposição. A essas oportunidades enriquecedoras nos conectamos com confiança, pensamento positivo e emoção (op. cit., p. 97).

A Física Quântica apresenta uma abertura para a espiritualidade e traz definitivamente a consciência para o palco das investigações científicas. Entretanto, temos hoje, devido ao modismo, muitas pessoas sem a menor bagagem acadêmica, sem o lastro cultural necessário, incapazes de resolver até mesmo uma equação de segundo grau, se arvorando em professores de Física Quântica e, assim, dando dessa ciência uma lamentável imagem (op. cit., p. 115).

Como se pode observar nessas transcrições, certas abordagens sobre a teoria quântica não estão necessariamente de acordo com a visão dos físicos, possivelmente contribuindo para criação de representações sociais que também não estejam de acordo com as idéias aceitas no campo da Física. Mais que isso, é relevante notar que a venda crescente e a necessidade de reedições de obras dessa natureza indica que existe interesse do público por temas ligados à Física Quântica.

Seguramente representações sociais da Física Quântica existem entre alguns grupos sociais, uma vez que as condições de emergência estão satisfeitas. Há grande dispersão de informações a este respeito, certamente há pressão à inferência entre alguns grupos, principalmente nos que consomem esta espécie de comunicação e, além disso, certos aspectos da teoria são alvo de focalização, sendo considerados mais importantes que outros para o sujeito, impedindo que haja uma visão global do objeto. Portanto, é importante evidenciar que idéias são disseminadas entre a população e chamar atenção para estas "quânticas alternativas", que podem gerar representações sociais.

Para entender o funcionamento, a evolução e as transformações que podem ocorrer com uma representação social é imprescindível conhecer a dinâmica das relações entre seu núcleo e 
sua periferia. Essa compreensão fornece bases para apontar até que ponto uma representação social pode funcionar como subsunçor para processos de aprendizagem e como, de posse dessas informações, é possível promover uma mudança representacional baseada na prática da sala de aula. Deve-se considerar que as representações

"circulam através da comunicação social cotidiana e se diferenciam de acordo com os conjuntos sociais que as elaboram e as utilizam. Por tudo isso, a pesquisa empírica das representações sociais não produz resultados replicáveis ou generalizáveis para outros contextos" (Sá, 1996, p. 22).

Deste modo, cada pesquisa em representações sociais exige a utilização de metodologia adequada ao caso que se deseja estudar, principalmente porque não há padrões a serem seguidos, mas apenas recomendações sobre a formulação do instrumento a ser utilizado. A pesquisa em representações sociais é plurimetodológica.

\section{Metodologia}

Com o intuito de investigar um grande número de pessoas, a melhor opção foi utilizar um instrumento de largo alcance, cuja análise de dados pudesse ser estatística. Optou-se pelo uso de questionários, onde foram utilizados dois testes de associação de conceitos e, ao final, uma etapa de identificação da escolaridade dos respondentes. Para elaborar os dois testes, foi realizada uma pesquisa prévia para determinar que palavras seriam utilizadas como estímulo no questionário.

Foram escolhidas dez palavras através de uma pré-associação via internet, na qual foi solicitada a associação, de qualquer espécie e espontânea, com o termo Física Quântica. A partir das associações captadas, foi elaborada uma lista com os termos de maior incidência e, a partir deles, escolhidos os dez termos finais. Os testes foram compostos por cinco palavras relacionadas diretamente à teoria - Física Quântica, incerteza, partícula, probabilidade e quantum - e outras cinco - alma, espiritualidade, pensamento, sobrenatural e sucesso - muito citadas porém estranhas à teoria..

O primeiro teste escolhido consiste em associar livremente palavras ao termo dado, é denominado Teste de Associação Escrita de Conceitos - TAEC - e permite determinar a proximidade semântica entre os conceitos dados. Já no TANC, ou Teste de Associação Numérica de Conceitos, o respondente deve atribuir valores numéricos para cada dupla de palavras fornecida. A grande vantagem dessa escolha é que ambos permitem que um grande número de pessoas possa participar e que a análise ocorra de modo estatístico. A estratégia dos testes é bastante simples e já foi utilizada em outros estudos na área de Ensino de Física (e.g., Greca \& Moreira, 2001; Santos \& Moreira, 1991). 
Para a análise das respostas foram utilizadas técnicas de Escalonamento Multidimensional e a Análise de Agrupamentos Hierárquicos (Kruskal, 1978; Santos \& Moreira, 1991). Na análise multidimensional são geradas representações geométricas, como mapas, que refletem a estrutura cognitiva do respondente. Esses mapas são obtidos a partir de matrizes de similaridade, onde cada célula reflete quão próximos são dois conceitos. $O$ grau de proximidade é obtido diretamente no caso do TANC, onde cada par de palavras-estímulo recebe uma numeração de 1 a 7 - quanto maior o valor, mais diferentes as duas palavras - e indiretamente no caso do TAEC, onde é calculado um coeficiente de correlação - segundo o método de Garskof \& Houston (1963) - que leva em consideração a posição de associações repetidas ao comparar-se cada dupla de palavras-estímulo.

De posse das respostas para cada sujeito, foram obtidas matrizes médias, com a similaridade atribuída em cada teste. Essas matrizes médias, para cada grupo em separado, constituíram os dados de entrada para o programa de tratamento estatístico, neste caso o SPSS 8.0. Foram obtidos dois mapeamentos para cada grupo analisado, um proveniente das matrizes do TANC e outro a partir das matrizes do TAEC.

Para completar a análise das representações sociais, buscou-se estabelecer que elementos faziam parte do núcleo e da periferia dessas representações. Para facilitar esta etapa, foi utilizada uma técnica adicional, de acordo com a teoria do núcleo central (Sá, 1996), aplicada simultaneamente ao TAEC e que consistiu em "pedir ao sujeito para efetuar ele mesmo sobre sua própria produção um trabalho cognitivo de análise, de comparação, de hierarquização" (Abric, apud. Sá, 1998, p. 91.). Solicitou-se aos sujeitos que marcassem hierarquicamente, com 1, 2 e 3, os três termos que consideravam mais importantes e relacionados com o termo "Física Quântica". As palavras marcadas supostamente compunham o núcleo e as outras a periferia.

\section{Resultados}

O questionário foi respondido por 236 estudantes de Ensino Médio durante o 10 semestre letivo de 2008. Destes alunos, 77 são de 10 ano, 72 de 2 ㅇ ano e 87 de 30 ano, todos da região de Porto Alegre - RS. Nas figuras 1,2 e 3 são apresentadas configurações provenientes das associações realizadas por esses alunos entre as palavras-estímulo fornecidas. 


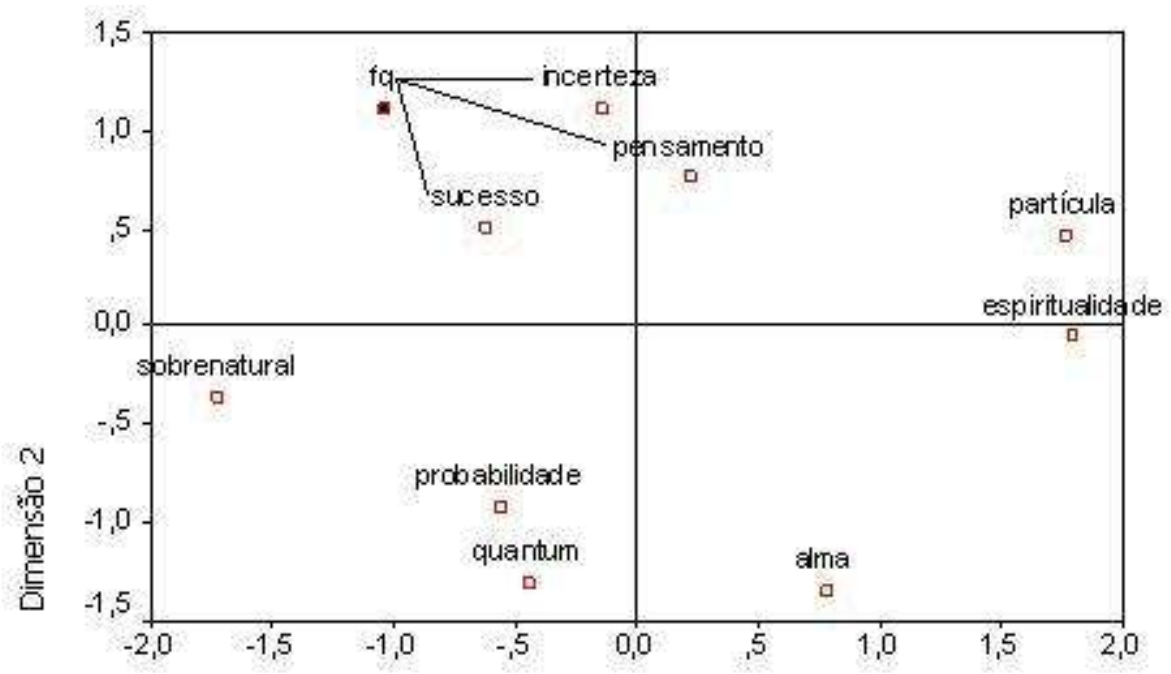

Dimensã̃o 1

Figura 1 - Diagrama em duas dimensões obtido a partir do TAEC para estudantes do 1o ano do Ensino Médio. (stress 0,23294 e RSQ 0,61235)

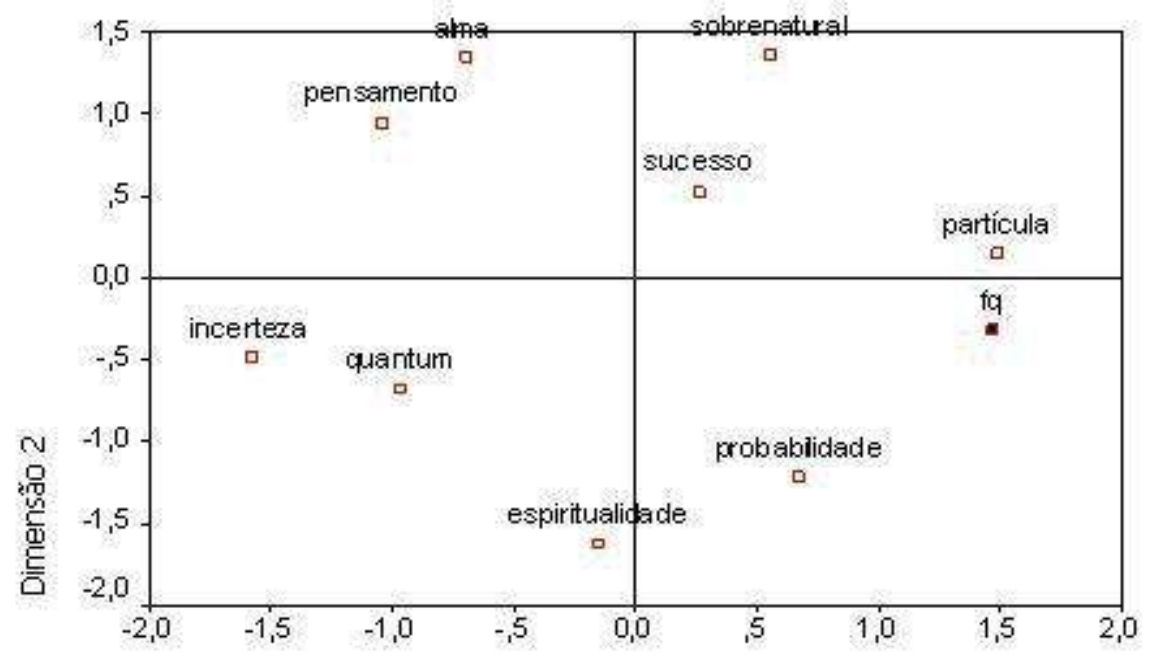

Dimensã̃o 1

Figura 2 - Diagrama em duas dimensões obtido a partir do TAEC para estudantes do 2 o ano do Ensino Médio. (stress 0,25430 e RSQ 0,47142)

Na configuração obtida para os dados do TAEC da 1a série (Figura 1), os termos mais próximos à Física Quântica (abreviada na figura como "fq") foram incerteza, pensamento e sucesso. Para o $2^{\circ}$ ano (Figura 2), observa-se a proximidade das palavras partícula, probabilidade, 
sobrenatural e, novamente, sucesso. Ambos sugerem a associação da quântica com termos advindos dos meios de comunicação.

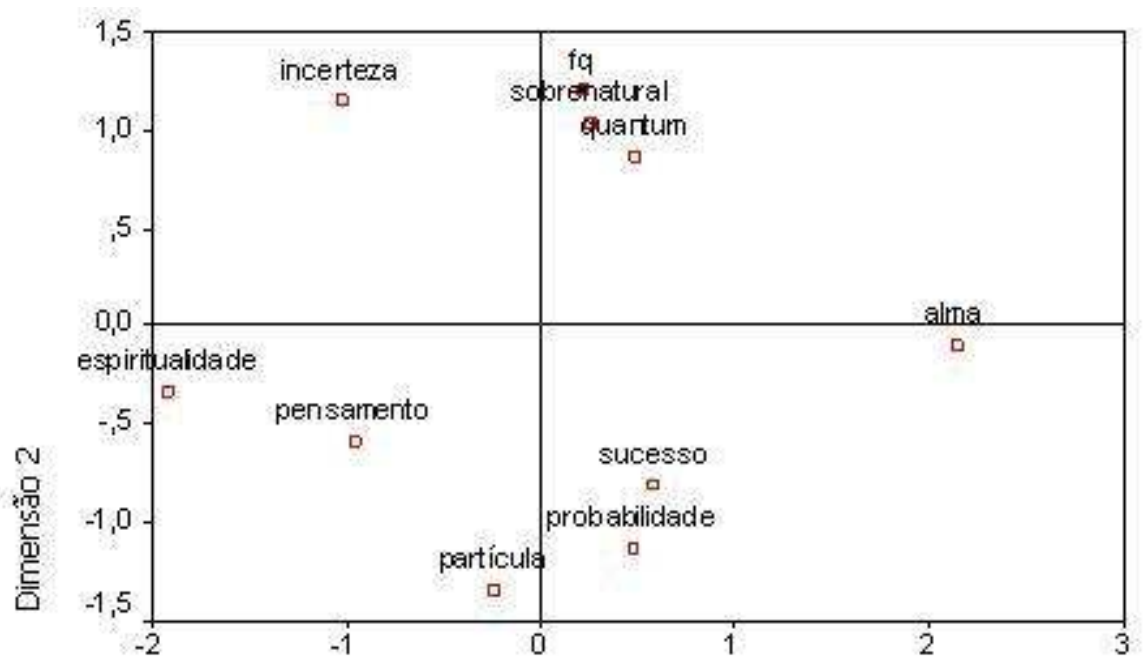

\section{Dimensã̃o 1}

Figura 3 - Diagrama em duas dimensões obtido a partir do TAEC para estudantes do 3o ano de Ensino Médio. (stress 0,28830 e RSQ 0,45173)

Para os alunos do 3ㅇ ano (Figura 3), também foi observada a proximidade do termo sobrenatural, além de quantum e incerteza. Ou seja, nas três séries foi verificada a proximidade atribuída a termos de dois universos que utilizam conceitos quânticos: por um lado proximidade com termos acadêmicos e, por outro, com termos alternativos. Na tabela 1 são apresentados dois exemplos de associações, cada um para um aluno diferente da mesma turma, de termos alternativos com a Física Quântica em cada série: na primeira coluna têm-se as respostas de dois alunos de 1 을 ano, na segunda coluna para o 20 ano e na última coluna exemplos de associações realizadas no 3으. ano. 
Tabela 1 - Exemplos de associações para o termo Física Quântica.

\begin{tabular}{|c|c|c|c|}
\hline Série: & 10 ano & 20 ano & 3o ano \\
\hline & & & Quantidade \\
& & & Energia 1 \\
& Complicado & Cálculo 1 & Força \\
Primeiro & MRUV 3 & Velocidade & Conducidade \\
exemplo: & Água 2 & Gravidade 3 & Elétron \\
& Bháskara & Cotidiano & Movimento 3 \\
& Contas 1 & Faculdade 2 & Volume \\
& & & Gerador \\
& & & Receptor \\
\hline & & & Cérebro \\
& & & Corpo humano 1 \\
& Força 3 & & Informática \\
& Queda & & Atualidade \\
& Tempo & Água 3 & Vibração \\
& Velocidade 2 & Medida & Investigação 3 \\
Segundo & Gravidade & Quantidade1 & Sentimento \\
exemplo: & Posição & Força 2 & Emoção \\
& Peso & Energia & Mente \\
& Água 1 & & Experiência \\
& Corrente & & Probabilidade 2 \\
& & & Sobrenatural \\
& & & Além \\
\hline
\end{tabular}

Esses exemplos sugerem que se existe, de alguma forma, o contato dos alunos com essas formas de divulgação, isto exerce influência em suas possíveis representações sociais sobre a quântica. Como não é comum que alunos de Ensino Médio tenham contato com essa teoria em sala de aula, supõe-se que seu único meio de interação com esse assunto seja através da mídia, isto é, os alunos tomam contato com uma quântica alternativa e constroem, ou começam a construir, representações sociais da Física Quântica.

\section{Conclusão}

Existe atualmente uma tendência, ou uma pressão, à inclusão de tópicos sobre Física Moderna e Contemporânea no Ensino Médio. A Física Quântica inclui-se nesta perspectiva. De acordo com a teoria da aprendizagem significativa, é necessário conhecer que idéias os alunos apresentam ao serem ensinados sobre esse assunto e o enfoque das representações sociais permite estudar que idéias são essas, sua estrutura e como são elaboradas e compartilhadas. 
Devido à crescente quantidade de obras e materiais de divulgação que apresentam interpretações alternativas sobre a teoria quântica, podem surgir diferentes interpretações sobre esta teoria, influenciando a elaboração de representações sociais. Segundo os dados obtidos para este estudo, é possível inferir a influência dos meios de comunicação, como os livros comentados aqui, nessas representações. No entanto, este estudo trata de uma investigação inicial e outros estudos também estão sendo realizados sobre o mesmo tema para outros grupos. Além dos diagramas aqui apresentados, estão sendo estudados outros provenientes do TANC - teste de associação numérica de conceitos - que não foram apresentados neste trabalho.

Sabendo que as informações veiculadas sobre a quântica participam na elaboração das representações sociais e que estas representações podem atuar como subsunçores no processo da aprendizagem significativa, justifica-se a necessidade de mais investigações nessa área. Porque os subsunçores podem funcionar como obstáculo à captação de significados cientificamente aceitos, mostra-se relevante compreender o universo dos estudantes e, assim, fornecer subsídios para melhorar a prática pedagógica.

Como diz Ausubel, o conhecimento prévio é a principal variável a influenciar a aquisição de novos conhecimentos. No caso das representações sociais da Física Quântica, assim como as conhecidas concepções alternativas no caso da Física Clássica, esse conhecimento prévio pode funcionar como obstáculo epistemológico.

\section{Referências}

ABRIC, J. C. O estudo experimental das representações sociais. In: Jodelet, D. As representações sociais. Rio de Janeiro: Eduerj, 2001. pp. 155-171.

AUSUBEL, D. P. The acquisition and retention of knowledge: a cognitive view. Dordrecht: Kluwer Academic Publishers, 2000. 212 p.

GARSKOF, B. \& HOUSTON, J. Measurement of verbal relatedness and idiographic approach. Psychological Review, Washington, v. 70, n. 3, pp. 277-288, mai. 1963.

GRECA, I. M. \& MOREIRA, M. A. O uso da análise multidimensional na pesquisa em ensino de ciências. Revista Brasileira de Pesquisa em Educação em Ciências: ABRAPEC, v. 1, n. 3, pp. 99110, set-dez. 2001.

JODELET, D. La representación social: fenómenos, concepto y teoría. In: Moscovici, S. (ed). Psicología Social, II. Barcelona: Paidós, 1986. pp. 469-494.

KRUSKAL, J. B. \& WISH, M. Multidimensional scaling. Bervely Hills: SAGE publications, 1978. 93 p.

LIMA, M. C. A. Quântica, espiritualidade e sucesso. Porto Alegre: Editora Age Ltda., 2007. 125 p. 
MATTOS, V. Medicina quântica. Curitiba: Editora Corpo e Mente, 2001. 307 p.

MENEZES, J. Inteligência quântica: aplicações da teoria quântica na transformação humana. Porto Alegre: Edições Besouro Box, 2006. 109 p.

MOLINER, P. Les conditiones d'émergence d'une représentation sociale. In: Moliner, P. (ed). Images et représentationes sociales. Grenoble: PUG, 1996. pp. 33-48.

MOREIRA, M. A. Aprendizaje significativo: un concepto subyacente. In: Moreira, M. A., Caballero, M. C. e Rodríguez, M. L. (orgs.). Actas del encuentro internacional sobre el aprendizaje significativo. Burgos, 1997. pp. 19-44. Traducción de Ma Luz Rodríguez Palmero.

MOSCOVICl, S. \& HEWSTONE, M. De la ciencia al sentido común. In Moscovici, S. (ed). Psicología Social, II. Barcelona: Paidós, 1986. pp. 679-710.

MOSCOVICl, S. Representações sociais: investigações em psicologia social. Petrópolis: Vozes, 2003. $404 \mathrm{p}$.

SÁ, C. P. A construção do objeto de pesquisa em representações sociais. Rio de Janeiro: Eduerj, 1998. $106 \mathrm{p}$.

SÁ, C. P. Núcleo central das representaç̧̃es sociais. Rio de Janeiro: Vozes, 1996. 189 p.

SANTOS, C. A. \& MOREIRA, M. A. Escalonamento multidimensional e análise de agrupamentos hierárquicos. Porto Alegre: Editora da Universidade, 1991. 172 p.

ZOHAR, D. O ser quântico. Uma visão revolucionária da natureza humana e da consciência, baseada na nova física. 14. ed. São Paulo: Editora Best Seller. 305 p. Tradução do original: The quantum self (1990).

ZOHAR, D. Sociedade quântica. São Paulo: Editora Best Seller, 2000. 424 p. Tradução do original: The quantum society (1993).

Thaís Rafaela Hilger: aluna do Programa de Pós-graduação em Ensino de Física da Universidade Federal do Rio Grande do Sul. thais.hilger@ufrgs.com

Marco Antonio Moreira: pesquisador e professor do Instituto de Física da Universidade Federal do Rio Grande do Sul.moreira@if.ufrgs.br

Fernando Lang da Silveira: pesquisador e professor do Instituto de Física da Universidade Federal do Rio Grande do Sul. lang@if.ufrgs.br 